\title{
GOVERNANÇA INTERFEDERATIVA NAS ENTIDADES METROPOLITANAS FEDERATIVAS
}

\author{
Edson Ricardo Saleme* \\ Renata Soares Bonavides**
}

\begin{abstract}
Resumo: Este trabalho versa sobre as vantagens da criação de entidades supramunicipais, tais como as regiões metropolitanas, aglomerações urbanas e microrregiões. Elas são fundamentais para o crescimento local. O Plano de Desenvolvimento Integrado é lei de referência da entidade autárquica criada pelo estado ou estados. Esta norma é a baliza do que se reconhece como governança interfederativa. Aqui se analisa o caso da AGEM - Baixada Santista, que se esforça pelo desenvolvimento regional. O Zoneamento Ecológico Econômico e Plano de Desenvolvimento Costeiro são referências fundamentais do PDUI local, que conduzirá a Região a um patamar superior, após a regular aprovação.
\end{abstract}

Palavras-chave: Governança Interfederativa; Baixada Santista; Pdui.

\section{COLLECTIVE GOVERNANCE AT THE METROPOLITAN ENTITIES IN BRAZIL}

Abstract: This paper deals with the advantages of creating a collective governance among municipal entities, such as metropolitan regions, urban agglomerations and microregions. Important to local growth. The Integrated Development Plan is the standard reference of the entity created (Metropolitan Agency) by the state or states. This law is the mark of what is recognized as a collective governance. Here we analyze the case of AGEM - Baixada Santista, which strives for regional development. The Economic Ecological Zoning and Coastal Development Plan are key references of the local PDUI, which will lead the Region to a higher level after regular approval.

Keywords: Collective Governance; Baixada Santista; Pdui.

\footnotetext{
* Doutor em Direito do Estado pela Universidade de São Paulo (1998). Atualmente é professor do Curso stricto sensu (Mestrado e Doutorado) em Direito Ambiental Internacional na Universidade Católica de Santos. Na graduação leciona na Universidade Paulista e UNISANTOS; professor de especialização da Escola Superior do Ministério Público de São Paulo, do IPOG, INOREG e Notável.

** Doutorado em Direito das Relações Sociais pela Pontifícia Universidade Católica de São Paulo (2008), Mestrado em Direito pela Universidade Metropolitana de Santos (2000) e Graduação em Direito pela Universidade Católica de Santos (1992). Atual Diretora da Faculdade, do Mestrado e Doutorado em Direito da Universidade Católica de Santos - UNISANTOS, onde leciona Direito Penal. Professora de Metodologia no Curso de Pós-Graduação Lato Sensu de Processo Civil e Coordenadora e Professora da Pós-Graduação Lato Sensu de Direito Penal, Processual Penal e Criminologia da Universidade Católica de Santos. Membro do Núcleo Docente Estruturante da Faculdade de Direito da Unisantos. É advogada criminal no escritório Bonavides Advogados Associados.
}

Rev. de Direito Urbanístico, Cidade e Alteridade | e-ISSN: 2525-989X| Brasília | v. 3 | n. 1 | p. 108 - 123 | Jan/Jun. 2017 


\section{INTRODUÇÃO}

O crescimento das cidades sem planejamento leva a uma expansão desordenada da urbe que repercute fundamentalmente em seu já precário funcionamento. As cidades brasileiras costumam ser formadas espontaneamente, sem precauções técnicas tomadas modernamente na formação de núcleos urbanos.

Com esse adensamento urbano espontâneo há, inexoravelmente, situações de riscos ambientais e sociais, agravando ainda mais a precariedade gerada pela aglomeração humana em áreas desprovidas de equipamentos adequados. O planejamento, não somente no início da vida citadina mas em sua evolução, é imperioso para se estabelecer qualidade de vida nos centros urbanos. Por esse motivo, há reiteradas críticas na disposição do art. 182 da Constituição Federal, que apenas impõe a municípios acima de vinte mil habitantes a elaboração de planos diretores. Mesmo contestado pela doutrina, há normas infraconstitucionais que ampliam essa obrigatoriedade, a exemplo do artigo 41 do Estatuto da Cidade (Lei 10.257/2001), o qual consigna situações diversas em que a confecção do plano diretor é cogente.

Diante do grande número de municipalidades existentes e do crescimento repentino de núcleos urbanos determinados, há locais em que uma entidade coletiva é vista como sendo a solução viável para se conduzir grande parte dos serviços comuns a todos eles, de forma satisfatória e menos onerosa. As competências constitucionais outorgadas aos municípios, sobretudo as que se referem a bens e serviços de interesse local, podem se adequar as atuais estruturas econômicas e viabilizar a consecução deles por intermédio de estrutura que agregue municípios vizinhos, geralmente conurbados geograficamente, criando uma rede convenientemente estruturada de forma a coordenar e distribuir em área determinada a infraestrutura requerida pelo adensamento de forma a se estabelecer formulas sustentáveis para a metrópole e, individualmente, de cada município.

A composição da entidade agregadora de municípios é disposta por lei complementar do estado ou estados a que se criará Região Metropolitana e seu intuito é estabelecer rede complexa de maneira a atender os interesses da coletividade de entes municipais, com participação efetiva de cada um deles nas decisões de órgão colegiado composto para decisões fundamentais. 
O ente formado pode ser exteriorizado em regiões metropolitanas, aglomerações urbanas ou microrregiões. Deve contemplar comissões e órgãos para discutir as necessidades locais resultantes da expansão da área metropolitana e que sejam fundamentais para a permanência jurídica e cooperação orgânica da estrutura supramunicipal criada. Essa entidade controlará os diversos fluxos existentes na região geográfica que possam inclusive depender de infraestrutura existente ou futura.

As questões que aqui se colocam pairam acerca das vantagens relacionadas à criação das entidades supramunicipais. São elas realmente importantes para o crescimento local ou seu surgimento se prende unicamente a possíveis vantagens que possam advir de uma reunião formada apenas para fins casuísticos? Quais as vantagens urbanas e ambientais que podem advir da união e no que consiste especificamente a governança interfederativa que parece colocar em risco o próprio conceito de autonomia municipal?

Nesse sentido, observa-se que a Constituição Federal dedicou um dispositivo normativo restrito em termos de conteúdo, simplesmente estabelecendo algumas indicações no que concerne à iniciativa da lei complementar que cria a entidade. É possível identificar com a junção de municípios a criação de uma entidade administrativa que possa suprir definitivamente as necessidades coletivas e gerar um suporte consistente para as municipalidades.

Esta pesquisa empregará o método hipotético-dedutivo com amparo em pesquisa bibliográfica com o intuito de se esclarecer as questões dispostas e confirmar ou não as hipóteses consignadas nesta introdução. O tema é extremamente atual e sua atualidade se configura a partir da aplicação da Lei n. 13.089/2015, o Estatuto da Metrópole, cujo intuito foi o regulamentar o dispositivo constitucional citado.

\section{REGIÕES METROPOLITANAS NA BAIXADA SANTISTA E A PREVISÃO DE IMPACTOS AMBIENTAIS}

As primeiras oito regiões metropolitanas brasileiras foram criadas por meio da Lei Complementar $n^{\circ}$ 14, de 08.06.73, que criou as Regiões Metropolitanas de São Paulo, Belo Horizonte, Porto Alegre, Recife, Salvador, Curitiba, Belém e Fortaleza. Em cada uma delas estabeleceu-se que haveria um Conselho Deliberativo, presidido pelo Governador do Estado, e um Conselho Consultivo, que a lei estadual deveria criar. Cada Estado estaria obrigado a prover, por expensas próprias, as despesas de manutenção do

Rev. de Direito Urbanístico, Cidade e Alteridade | e-ISSN: 2525-989X| Brasília | v. 3 | n. 1 | p. 108 - 123 | Jan/Jun. 2017 
Conselho Deliberativo e do Conselho Consultivo. Esse Conselho Deliberativo seria o responsável pela coordenação e execução de programas e projetos de interesse regional e focando, sempre que possível, na unificação dos serviços considerados comuns. Também se responsabilizaria pelo Plano de Desenvolvimento Integrado da Região (PDUI), constando nele a programação dos serviços comuns.

A vigente Constituição Federal outorgou a possibilidade de criação e organização de Regiões Metropolitanas aos estados federados, nos termos do $\S 3^{\circ}$ do art. 25 da CF. Nesse diapasão, o art. 13 do Estatuto da Metrópole (Lei no 13.089/2015) também prescreveu no mesmo sentido, que por meio de lei complementar se poderiam criar regiões metropolitanas, aglomerações urbanas e microrregiões. O intuito seria reunir municipalidades conurbadas para a organização, planejamento e a execução de funções públicas de interesse comum.

O parágrafo único do art. $3^{\circ}$ do Estatuto da Metrópole indicou que a promoção da "governança interfederativa" seria efetivada por essas entidades formadas por municípios de um ou vários estados. Deixa claro que a validade delas depende de aprovação do Legislativo de cada Estado envolvido. Importante que na aplicação da Lei $\mathrm{n}^{\circ}$ 13.089/2015 consignou-se que deveriam também ser observadas as normas gerais de direito urbanístico estabelecidas na Lei $\mathrm{n}^{\mathrm{o}} 10.257$, de 10 de julho de 2001, autodenominada de Estatuto da Cidade,

A norma criadora dessas entidades deveria relacionar os municípios que a formam, os campos funcionais e as funções públicas de interesse comum, com indicações do critério técnico adotado, de maneira a justificar a criação da novel entidade territorial, aí incluindo as formas de controle social da organização. Também se indicaria a estruturação da entidade interfederativa, com a respectiva organização administrativa, a alocação dos recursos necessários e o procedimento de prestação de contas a ser adotado.

A realidade comprova que a criação de entidades coletivas, em sua maioria, não obedece a critérios técnicos ou opções objetivas, que possam comprovar tecnicamente as vantagens da união, sobretudo na prestação dos serviços comuns. A sua institucionalização, muitas vezes, sucumbe a pressões políticas, sobretudo no que tange à inclusão de municípios que nela deveriam estar compreendidos.

O Observatório das Metrópoles (2017) fez análise do quadro institucional das regiões metropolitanas (RMs) brasileiras, no que concerne às entidades criadas antes e depois da norma contida no $\$ 3^{\circ}$ do art. 25 da Constituição Federal, atualmente também consignada no

Rev. de Direito Urbanístico, Cidade e Alteridade | e-ISSN: 2525-989X| Brasília | v. 3 | n. 1 | p. 108 - 123 | Jan/Jun. 2017 
artigo $3^{\circ}$ da Lei $n^{\circ} 13.089 / 2015$. Esse monitoramento se concentrou na atualização do universo metropolitano oficial a partir da coleta de informações em órgãos como o Ministério da Integração, o Governo Federal, as Assembleias Legislativas e os Governos Estaduais. Atualizando as informações contidas no site com informações prestadas pela AGEM da Baixada Santista, o Brasil possui cerca de 42 entidades coletivas, incluindo as 3 regiões integradas de desenvolvimento econômico (RIDEs). É possível afirmar ainda que em algumas RMs há colares metropolitanos, áreas de expansão metropolitana e entorno metropolitano definidos em lei. ${ }^{1}$

Os modelos mais comuns empregados para a delimitação de áreas para formação desses grupamentos, segundo A. Delonrezo Neto (1972, p. 29) podem se resumir nos seguintes: melhor conhecimento de determinado conjunto regional, necessidade de se reagrupar os múltiplos fluxos que existem no território nacional estabelecendo-se o que denomina de "regiões polarizadas" e, em como último argumento, necessidade de ação em determinada parte do território a partir de regras de competência, tal como ocorria, por exemplo, em uma bacia fluvial.

O autor referido, na época que escreveu, mencionou o prejuízo das entidades municipais e regionais no Brasil em decorrência da incoerência da própria estrutura federal e da situação financeira que acarreta a discriminação rígida de competências. A situação permanece inalterada em face da Constituição Federal vigente, tendo em vista a escassez orçamentária que essas entidades se encontram.

$\mathrm{Na}$ verdade, para que exista verdadeiro interesse em reunir municípios, deve ser viabilizada a possibilidade de um entorno atrativo da política urbana a fim de se dinamizar determinada região em processo de reunião. Como bem sublinhou Klink (2001, p. 33), o entorno da política urbana deve possuir adequada infraestrutura de comunicação, boa qualidade de serviços urbanos, bons recursos tecnológicos, da mão- de-obra e do meioambiente. Por outro lado, problemas sociais deveriam também ser exibidos pelas cidades e regiões a fim de não se perder a atratividade, oferecendo, a par disso, ampla gama de serviços

\footnotetext{
${ }^{1}$ Observatório das Metrópoles. Instituto Nacional de Ciência e Tecnologia. IPPUR/UFRJ CNPQ FAPERJ. O Instituto observou que haveria o total de 35 Regiões Metropolitanas. Porém, o número atual gira em torno das 42 entidades coletivas criadas por diversos Estados da Federação brasileira. Disponível em <http://www.observatoriodasmetropoles.net/download/observatorio_RMs2010.pdf>. Informação obtida na AGEM Baixada Santista, em 15.4.2017. Acesso em 03.05.2017.
} 
sociais, culturais e urbanísticos para atrair as pessoas.

A constituição de regiões metropolitanas, aglomerações urbanas e microrregiões justifica-se legalmente pela conveniência em se integrar os chamados serviços comuns. Para Clementina de Ambosis trata-se de integrar ou tornar inteiro algo que está fragmentado, integralizando o que está segmentado em municípios pela divisão político- administrativa. $\mathrm{O}$ resultado é sim um novo ente que não substitui os municípios. É a reunião deles. É verdadeiramente uma reunião de funções públicas do Estado ou de caráter intermunicipal restritas a região. ${ }^{2}$

A exigência de lei complementar para a formação dessas entidades se revela não somente na integração de funções públicas inerentes a entidade municipal, mas também as do Estado a que se inserem. Aqui reside, sobretudo, o interesse ambiental. Ao se unir uma entidade em região metropolitana, aglomeração urbana ou microrregião há nítida participação estatal por razões de cunho ambiental, que aquela entidade federativa poderia auxiliar na discussão e tomada de decisões referentes às ações impactantes e sua possível mitigação.

A criação de entidade conjunta, como as aqui enfocadas, reforça a percepção de que o estado necessita da cooperação de entidades municipais conurbadas para que se decida a melhor opção em termos de viabilização de políticas regionais. Não basta a criação de planos estaduais abrangentes que busquem equacionar problemas de índole genérica. A possibilidade de se reunir regionalmente entidades com características e necessidades semelhantes pode também revelar um conjunto de peculiaridades comuns que exijam um conjunto de medidas mais apropriado ao que se realmente necessita em termos de melhor composição de infraestrutura, mormente com finalidade de se atrair investidores ou mesmo empreendimentos para o desenvolvimento local.

Considerando ainda que as normas mais modernas, tal como o Estatuto da Metrópole, exigem uma participação coletiva atuante, denota um aperfeiçoamento democrático nas tomadas de decisões. Esse tratamento regional descentralizado inclina-se a uma nova preocupação em termos de governabilidade. Este é o motivo pelo qual a conformação da estrutura interfederativa deve estabelecer não somente a organização da entidade, mas também

\footnotetext{
${ }^{2}$ AMBROSIS, Clementina de. Regiões metropolitanas, aglomerações urbanas e microrregiões. In Estatuto da Cidade (Fundação Prefeito Faria Lima - CEPAM). Coord. MOREIRA, Mariana. São Paulo: 2001, págs.165 - 176.
}

Rev. de Direito Urbanístico, Cidade e Alteridade | e-ISSN: 2525-989X| Brasília | v. 3 | n. 1 | p. 108 - 123 | Jan/Jun. 2017 
a forma de alocação de recursos e como os administradores devem prestar as contas.

A seguir será enfocada a questão da governança interfederativa e as formas de controle social impostas as entidades formadas. Observa-se que grande parte dos conceitos empegados pela norma baseia-se na terminologia do IBGE (Instituto Brasileiro de Geografia e Estatística), que inclusive fornece os qualificativos do que seja metrópole e aglomeração urbana.

\section{DA GOVERNANÇA INTERFEDERATIVA}

Inicialmente é fundamental esclarecer que a gestão metropolitana por meio da governança interfederativa é tarefa complexa que envolve as dificuldades de coordenação inerentes a qualquer entidade sujeita a decisões colegiadas, que muito debate até se chegar ou não a um denominador comum. Existem inúmeras áreas que podem ser beneficiadas com um bom gerenciamento de recursos e provisões que a entidade autárquica deve manejar. Os componentes complexos, no que tange a atração empresarial para o polo, bem como a solução dada ao ânimo dos atores envolvidos é fator a ser habilmente manejado para uma resposta satisfatória. Dificultosa também a questão ambiental. Isso porque, na medida que a região se torna atrativa, o volume de impactos cresce na proporção direta do número de empreendimentos.

Em um primeiro momento, a entidade regional é vista como sendo local que poderia se aplicar instrumentos próprios a fim de se evitar dispersão desnecessária de recursos, deterioração de seu entorno e o crescimento territorial desordenado, o que resultaria em uma baixa qualidade de vida com todos os percalços correspondentes (pobreza, desemprego, problemas de mobilidade, deterioração de fontes hídricas, saneamento deficiente e degradação ambiental). Fernanda Magalhães (2017, p. 22), na introdução da obra Regiões Metropolitanas no Brasil, refere-se a um paradoxo de desafios e oportunidades que permeiam a criação dessas entidades.

A autora segue em sua ilação reafirmando que para as prefeituras é dificultosa a questão de, sem apoio e de maneira singular, enfrentarem desafios que ultrapassem seus limites territoriais. Nesse sentido, deve gerir suas ações públicas "em diversos horizontes temporais", realizáveis em curto, médio e longo prazo. Essa forma de atuação ultrapassaria os arranjos políticos tradicionais em evolução a modelos mais modernos de forma a gerar o que denominou de "contrato-programa consensuado" na ausência de um mecanismo de gestão 
formal que possa colocar em risco a execução e sustentabilidade de determinado projeto metropolitano.

Relativamente ao processo decisório, contudo, importante o que sublinha Raquel Rolnik (2001, p.115 - 121) ao afirmar que os processos de negociação coletiva que não levavam em consideração os grupos envolvidos e nem tinham um planejamento racional levavam a um "discurso esquizofrênico" pois, de um lado, os planos reiteravam modelos e padrões de uma cidade racionalmente produzida. De outro, o destino da cidade seria negociado por padrões econômicos, dia-a-dia, que produziriam um espaço três vezes maior situado em uma zona intermediária entre o legal e o ilegal, completamente fora dos padrões existentes na área planejada. Nesse sentido, o Estatuto da Cidade, como lei agregadora e que dispõe acerca dos problemas municipais, procura outorgar ao poder público a possibilidade concreta de mediar os problemas urbanos.

O processo de descentralização das funções tem como objetivo fundamental aumentar a competitividade e promover o crescimento da economia local, como afirma Eduardo Rojas (2017). A dificuldade de gestão metropolitana resulta de estruturas obsoletas e ineficientes em termos de relações governamentais que definem atribuições e responsabilidades nos diversos níveis decisórios. Isto é ainda mais agravado porque não há órgãos eleitos para debater questões metropolitanas. Nesse sentido, expandem-se os arranjos imediatos, constituídos em cada ocasião, a fim de gerar soluções pontuais. Este detalhe específico, como bem sublinhou o autor, enfraquece a responsabilização (accountability).

Interessante o exemplo dado pelo autor no que tange ao modelo "monista", por meio do qual o governo local presta todos os serviços atinentes a sua circunscrição e o modelo "dualista", também conhecido como modelo metropolitano ou supranacional, por meio do qual, questões complexas e que podem gerar significativo grau de externalidades são prestadas por essa entidade supramunicipal, que exerceria um papel com melhor desempenho e impactos reduzidos ou mitigados. O autor oferece o exemplo de Santiago do Chile. Assinala que diversos municípios de região metropolitana firmaram acordos com vistas à remoção de resíduos sólidos e ainda criaram fórmulas para a despoluição ambiental para a área metropolitana.

No Estado de São Paulo, por exemplo, há experiência significativas em gestão conjunta intermunicipal para coordenação de determinadas intervenções em prol do ambiente. Há 
programas de gestão de bacias hidrográficas, inclusive com a participação de mais de um ente federativo para coordenação da proteção ambiental. Existem diversos acordos em andamento que comprovam uma preocupação permanente na coordenação de ações que possam minimizar os impactos provenientes de diversas ações antrópicas.

A governança interfederativa deve ser suficiente para aportar um conjunto de medidas que possam proporcionar uma votação esclarecida dos entes envolvidos a fim de se decidir entre opções monistas ou dualistas. Isso sem falar da possiblidade de criação de comitês para estudo e operação de locais considerados ambientalmente frágeis e que possam gerar impactos negativos em uma gestão prestada sem os necessários cuidados. Assim, a opção, diante das possibilidades existentes é a composição de uma entidade supramunicipal que, democraticamente e com apoio da população local, possa prestar serviços com a cooperação privada. Por exemplo, em matéria de saneamento ambiental, não haveria mais conflito a partir de um planejamento integrado. Nesse sentido, tem-se que uma nova estruturação institucional do saneamento ambiental eliminaria funções concorrentes entre os entes federados e permitiria a cooperação de investimentos federais, estaduais, municipais se combinem com os investimentos privados, nos termos de um arcabouço jurídico-político devidamente organizado e sistematizado. ${ }^{3}$

\section{GOVERNANÇA E LEI COMPLEMENTAR N 140, DE 2011 E PDUI}

Um dos temas complexos que trata o Estatuto da Metrópole, além da governança interfederativa, cujo conceito é novo, é a obtenção de licenciamento para as intervenções que deveriam ser efetivadas na circunscrição que ocupa a metrópole pela autarquia criada para administrar a Região Metropolitana ou outra entidade coletiva. Trata-se de assunto relevante que muitas vezes torna a ação obstada por conta da falta do imperioso licenciamento, cuja ausência ou não autorização obstrui a realização de determinada obra ou serviço imprescindíveis para a sustentabilidade local.

A Lei Complementar n 140, de 2011, regulamentou os incisos III, IV e VII do caput do parágrafo único do art. 23 da Constituição Federal estabelecendo possibilidade de cooperação

\footnotetext{
${ }^{3}$ BRASIL. Ministério das Cidades. Política nacional de desenvolvimento urbano. In cadernos MCidades desenvolvimento urbano. Novembro de 2004.
}

Rev. de Direito Urbanístico, Cidade e Alteridade | e-ISSN: 2525-989X| Brasília | v. 3 | n. 1 | p. 108 - 123 | Jan/Jun. 2017 
entre os entes federativos em ações administrativas decorrentes do exercício da competência comum relativas à proteção ambiental. Logo, em seu art. $4^{\circ}$, estão relacionados os instrumentos de cooperação institucional, que podem ser firmados por prazo indeterminado. Também permitem a delegação de um ente federativo a outro. Estas formações entre entidades públicas seriam mecanismos de viabilizar o desenvolvimento sustentável harmonizando e integrando políticas governamentais. $\mathrm{O}$ rol de atribuições previsto no art. $7^{\circ}$ permite que essa entidade plurifederativa possa não somente "formular, executar e fazer cumprir a Política Nacional do Meio Ambiente" como também promover "integração de programas"; colaborar com o SINIMA (Sistema Nacional de Informações ao Meio Ambiente), que já ocorre em alguns Estados, de maneira espontânea; defina espaços territoriais; estabeleça zoneamento; controle produção e comercialização de substâncias que possam gerar riscos ambientais; exerça controle e fiscalize atividades e exerça o controle ambiental em todas as frentes.

Considerando que a atuação das entidades supramunicipais pode gerar a sobreposição de atuações, a Lei Complementar $n^{\circ} 140$, de 2011, pode ser empregada para a criação de outra especialmente formada, podendo inclusive ser composta pelos mesmos membros da entidade coletiva, para a realização de atividades impactantes ou de gestão de algum serviço público, além de evitar problemas derivados da atuação de diversos atores estatais. Verdadeiramente já há fórmulas de intervenção supramunicipal, com a inclusão de entes federativos diversificados por meio de instrumentos de cooperação diversa

Para melhor solucionar alguns impasses o PDUI - Plano Diretor Urbano Integrado, cuja função é coletar e consignar as diretrizes fundamentais para a atuação da entidade criada pela lei complementar, pelo período máximo de dez anos, tem também a função de discutir, por meio de seus conselhos ou câmaras, o que sejam "funções de interesse comum" para unificar as necessidades dos entes federativos pertencentes aquela coletividade. Esse plano realmente é fundamental para que se possa estabelecer metas de grande, curto e médio prazo de maneira a prover a região com a prestação de serviços e obras necessárias à boa infraestrutura regional.

A articulação pública desse instrumento deve ser, ao mesmo tempo, suficiente para que todos os entes federativos se manifestem: municípios e estados envolvidos (se houver mais de um conforme o Estatuto da Metrópole prevê), assim também prever participação popular, fundamental em todos os processos decisórios da atualidade.

Ainda que esse plano possa consignar questões metropolitanas que exijam abordagens 
interfederativas, seu conteúdo não pode ser estruturado de forma a engessar a efetiva condução de negócios pela entidade supragovernamental. O que se busca evitar a qualquer custo é uma norma elaborada de tal forma que a materialização do seu conteúdo, durante sua vigência, possa ser obstada por excesso de elementos que venham a constituir verdadeiros entraves à gestão adequada.

A ação legiferante constitucional e legal tem por costume criar condições tais que a lei se constituiria o único instrumento efetivo de se viabilizar ações formalmente adequadas. $\mathrm{O}$ princípio da legalidade do artigo 37 da Constituição Federal pode ser considerado uma das bases para atuação da Administração precedida por mandamento legal prévio. Entretanto, não se pode com ele inviabilizar a atuação de uma entidade criada por lei, com orçamento e dotação próprios, com plano de ações também autorizado previamente (PDUI) e também sujeito à aprovações e fiscalizações populares permanentes (orçamento participativo, audiências públicas e outros instrumentos legais viáveis). Isso sem falar da prestação de contas permanente dos administradores da entidade e do Tribunal de Contas responsável.

Pode-se questionar como manter o poder público e a população atenta a esse quadro em que sua participação é realmente fundamental. A SEMPLA - Secretaria Municipal de Planejamento Urbano do Município de São Paulo (Sempla, p.183), por exemplo, adotou estratégia digna de menção. Elaborou projeto de lei durante o primeiro ano de mandato, quando há maior empenho dos esforços políticos do Executivo e do Legislativo. Estabeleceuse, na época, um grupo intersecretarial com atores dos diversos entes reunidos para exposição das propostas. Desta forma viabilizou o recolhimento de críticas e sugestões, além da possibilidade de se incluir alterações indicadas no debate. Diante dessa sistemática, logrou-se uma proposta e sua aprovação ocorreu de maneira diligente pelos respectivos legislativos. $\mathrm{O}$ plano estabeleceu como metas fundamentais os seguintes assuntos: uso e ocupação do solo, circulação viária e de transporte e plano municipal de habitação.

No PDUI da Região Metropolitana de São Paulo (RMSP. PDUI, 2017) reconhece-se a necessidade de participação do setor produtivo e da sociedade na confecção do Plano, que englobe questões metropolitanas que ultrapassam os limites municipais. Os assuntos essenciais que devem ser abordados e englobam os interesses interfederativos, nos termos do que está disposto seriam: esgotamento sanitário, macrodrenagem, destinação de resíduos sólidos, aproveitamento de recursos hídricos considerando as possibilidades de integração dos 
sistemas produtores e as projeções de demanda; disponibilidade de energia elétrica e de recursos de telecomunicações; entraves de infraestrutura de atendimento à população e de apoio à atividade econômica.

O PDUI, desta forma, para se transformar em um instrumento formalmente adequado, deve ser aprovado e transformado em lei pela Assembleia Legislativa do estado ou dos estados a que pertencerem os entes reunidos. Antes desta aprovação formal deve ainda passar por audiências públicas que possam melhor discutir assuntos de interesse coletivo da Região.

\section{5 . EXPERIÊNCIAS DA REGIÃO METROPOLITANA DA BAIXADA SANTISTA}

Inicialmente criou-se uma reunião de municípios, por meio do Decreto-Lei Complementar $n^{\circ} 7$, de 6 de novembro de 1969 e suas alterações e regem-se pelas disposições da Lei Complementar nº 815, de 30 de julho de 1996. Atualmente a Agência Metropolitana da Baixada Santista (AGEM), tem como autorização legislativa de funcionamento a Lei Complementar Estadual n ${ }^{\circ}$ 853, de 23 de dezembro de 1998, como entidade autárquica com sede e foro em município da Região Metropolitana da Baixada Santista. Inicialmente vinculava-se à Secretaria de Transportes Metropolitanos do Estado de São Paulo (AGEM, 2017). Possui autonomia administrativa, financeira e patrimonial e possui todos os privilégios comuns às autarquias públicas.

Importante passo dado por essa Agência da Baixada Santista foi a criação de um Plano de Desenvolvimento Estratégico local como fórmula de planejamento regional. Isso, uma vez aprovado, poderia se converter em um PDUI. Atualmente pode arrecadar receitas próprias ou outras que lhe sejam delegadas ou transferidas, inclusive multas e tarifas relativas a serviços prestados. Pode fiscalizar a execução das leis que dispõem sobre a região metropolitana e aplicar as respectivas sanções. Tem como objetivo também estabelecer metas, planos, programas e projetos de interesse comum, bem como fiscalizar e avaliar sua execução. Ainda tem a permissão de promover desapropriação de bens declarados de utilidade pública, quando necessário à realização de atividades de interesse comum.

Instituiu-se para melhor condução da entidade a criação do CONDESB - Conselho de Desenvolvimento da Região Metropolitana da Baixada Santista. Atualmente é formado por representantes das prefeituras daquela Região Metropolitana, bem como representantes do Governo do Estado, indicados entre as secretarias que atuam na localidade.

Rev. de Direito Urbanístico, Cidade e Alteridade | e-ISSN: 2525-989X| Brasília | v. 3 | n. 1 | p. 108 - 123 | Jan/Jun. 2017 
Importante sublinhar que o Conselho tem caráter normativo e deliberativo. Cuida de temas que podem ser considerados de interesse comum da Região. Importante frisar que a participação de seus representantes é realizada de igual forma entre o conjunto das prefeituras e os representantes do Estado. Esse órgão especifica as funções locais públicas de interesse comum.

Essa entidade ainda possui suporte financeiro garantido pelo Fundo de Desenvolvimento Metropolitano da Baixada Santista, cujo propósito é viabilizar o suporte econômico das ações devidamente planejadas, no que tange às funções públicas de interesse comum entre o Estado e os municípios integrantes da Região, devidamente consignadas em plano estruturado aprovado por lei. Certamente, como visto, este não seria o único meio de obtenção de receita. Porém, o principal.

Outro elemento importante na localidade é que se desenvolve na Baixada Santista atividades industriais, portuárias e logísticas, como retrata a edição ZEE-Baixada Santista, editada pela Secretaria do Meio Ambiente do Estado de São Paulo (2013, p.10). Nesse informe se relata que o crescimento das cidades componentes da entidade e o aumento da demanda de água, energia, habitação e saneamento público, bem como a descoberta e exploração da camada de pré-sal e da expansão e modernização do Porto de Santos, implicou em impactos e sociais para a Região.

Assim, o Plano Estadual de Gerenciamento Costeiro (Decreto no 47.303/2002) já previu a constituição de grupos colegiados, compostos por representantes do Estado, municípios e da sociedade civil, responsáveis pela elaboração de instrumentos de gestão local que dispusessem acerca da regulamentação de instrumentos previstos em seus dispositivos, sobretudo o Zoneamento Ecológico-Econômico. Este não poderia deixar de complementar outro já existente no Setor Costeiro do Litoral Norte, de forma a consolidar esse mesmo Plano (idem, p.11).

O Zoneamento Ecologico-Econômico é, nos termos do art. $2^{\circ}$ do Decreto nº 4.297/02, “instrumento de organização do território a ser obrigatoriamente seguido na implantação de planos, obras e atividades públicas e privadas, estabelece medidas e padrões de proteção ambiental destinados a assegurar a qualidade ambiental."

Esse Zoneamento, como bem remarca André Lima (2006, p.241), é instrumento da Política Nacional do Meio Ambiente. Está atrelado aos princípios de direito ambiental. Possui 
relação estreita com as unidades de conservação criadas e a Política Nacional de Recursos Hídricos. Influencia diretamente na gestão desses sistemas. Este zoneamento possui duas fases essenciais: o planejamento, que se dá a partir de estratégias baseadas em diagnósticos e diretrizes e normas de zoneamento, que se obtém diante da identificação peculiar do território, suas características e funcionalidades. O poder vinculante que pode ter esse instrumento, em atividades públicas ou privadas, está condicionado diretamente às diretrizes contidas em normas jurídicas a serem criadas para determinada circunscrição.

As informações precedentes denotam que já existe extenso trabalho normativo por parte dos gestores da Região Metropolitana da Baixada Santista. Há, igualmente, um PDUI que pode ser transformado em lei, caso seus elementos sejam amplos e dê alguma margem discricionária para a atuação administrativa. Isso é essencial para que de fato exista uma atuação administrativa que possa efetivamente trabalhar em prol da realidade existente. Tudo deve ser devidamente levado à aprovação popular e debatido em audiências públicas a fim de se obter um instrumento legítimo. Não se pode também olvidar da formação de comissões temáticas para debater o numeroso rol de assuntos que compõe a estruturação da norma.

\section{CONSIDERAÇÕES FINAIS}

Diante da pesquisa realizada são inegáveis as vantagens na criação de entidades supramunicipais, tais como as regiões metropolitanas, aglomerações urbanas e microrregiões. Elas são realmente importantes para o crescimento local e não deve apenas atender a fins casuísticos. As vantagens urbanas e ambientais a serem oferecidas pela reunião dependem do nível de organização que a entidade autárquica, responsável pela gestão coletiva da entidade, vier a conduzir de maneira adequada o que o Estatuto da Metrópole denomina governança interfederativa. Esta nova maneira de condução de negócios não põe em risco o conceito de autonomia municipal. Na verdade, objetiva unificar as necessidades coletivas, após efetiva verificação de suas vantagens, nas câmaras temáticas constituídas pela autarquia regional. Após este passo devem propor, caso a prestação de serviços ou realização de obras seja impactante, uma avaliação de impactos ambientais, com todas as precauções exigidas, nos termos da Lei Complementar $\mathrm{n}^{\circ} 140$, de 2011. Sequencialmente, pode prestar a contento serviços então que se desconcentravam e que, após sua consumação, passam a ter uma reunião satisfatória, capaz de responder pelas necessidade locais, bem como eventuais ampliações decorrentes do número de habitantes ou outras variáveis existentes naquela região.

Rev. de Direito Urbanístico, Cidade e Alteridade | e-ISSN: 2525-989X| Brasília | v. 3 | n. 1 | p. 108 - 123 | Jan/Jun. 2017 
É possível considerar que a Região Metropolitana da Baixada Santista já possui um PDUI, que deveria ser transformado em lei estadual, devidamente discutido e enquadrado nas normas vigentes e sobretudo ao que prescreve o Zoneamento Ecológico Econômico (ZEE), que também está de acordo com o Plano Estadual de Gerenciamento Costeiro (Decreto $\mathrm{n}^{\circ}$ 47.303/2002) e outras normas locais e regionais. Recentemente, com a possibilidade de exploração do pré-sal previu-se grande estimulo de trabalho e renda, o que efetivamente não ocorreu em decorrência da queda das commodities de petróleo.

O grande êxito dessas entidades culminou com a criação da formação Macrometrópole Paulista (MMP) pela EMPLASA - Empresa Paulista de Planejamento Metropolitano, que está contribuindo com sua vasta experiência em planejamento na criação dos Planos de Desenvolvimento Integrado das entidades coletivas. Trata-se da constituição de um dos maiores aglomerados urbanos do Hemisfério Sul. Nele estão incluídas: a Região Metropolitana de São Paulo (RMSP), que se situa entre as seis maiores do mundo, além das RMs da Baixada Santista, de Campinas, de Sorocaba e do Vale do Paraíba e Litoral Norte.

O grande desafio que se tem atualmente é a aprovação do PDUI em lei estadual. Como a sistemática constitucional estabelece esta obrigatoriedade, busca-se a formação de uma norma mais genérica de forma a não restringir a atuação administrativa das entidades autárquicas regionais, que já possuem orçamento e planejamento aprovados. Há orientação, ainda, em se estabelecer um macrozoneamento da região a fim de melhor mapeá-la e ter melhores resultados de gestão, o que deve ainda ser objeto de deliberação. Outros elementos que devem ser discutidos, juntamente com o PDUI seriam os planos setoriais, de mobilidade e logística, de gestão de resíduos sólidos, cicloviário metropolitano, de turismo regional, entre outros de grande importância.

\section{REFERÊNCIAS BIBLIOGRÁFICAS}

AGEM. Agencia Metropolitana da Baixada Santista. Disponível em < http://www.agem.sp.gov.br/agem-finalidade/>. Acesso em 8.05.2017.

AMBROSIS, Clementina de. Regiões metropolitanas, aglomerações urbanas $e$ microrregiões. In Estatuto da Cidade (Fundação Prefeito Faria Lima - CEPAM). Coord. MOREIRA, Mariana. São Paulo: 2001, p.165 176.

MAGALHÃES, Fernanda. Regiões Metropolitanas no Brasil: um paradoxo de desafios e oportunidades.

Disponível em 
<http://services.iadb.org/wmsfiles/products/Publications/36045064.pdf>, acesso em 03.05.2017.

DELORENZO NETO. A. A reorganização das áreas metropolitanas (urbanização e descentralização). São Paulo: Livraria Pioneira Editora, 1972, p. 29.

KLINK, Jeroen Johannes. A cidade-região (regionalismo e reestruturação no grande ABC paulista. Rio de Janeiro: DP\&A, 2001, p. 33.

LIMA, André. Zoneamento Ecológico-Econômico à luz dos direitos socioambientais. Curitiba: Juruá, 2006.

ROJAS, Eduardo. Governança de regiões metropolitanas da América Latina. Disponível em <http://services.iadb.org/wmsfiles/products/Publications/36045064.pdf>, acesso em 03.05.2017.

ROLNIK, Raquel. Planejamento e gestão: um diálogo de surdos. i Regiões metropolitanas, aglomerações urbanas e microrregiões. In Estatuto da Cidade (Fundação Prefeito Faria Lima - CEPAM). Coord. MOREIRA, Mariana. São Paulo: 2001, p.115-121.

SÃO PAULO. Plano Diretor Estratégico do Município de São Paulo 2002 - 2012 - Sempla (org). São Paulo: Prefeitura Municipal de São Paulo, 2004.

SÃO PAULO. ZEE Baixada Santista.: zoneamento ecológico-econômico - setor costeiro da Baixada Santista/ Secretaria do Meio Ambiente do Estado de São Paulo. Coordenadoria do Planejamento Ambiental. Org.: Luiz Roberto Numa de Oliveira. São Paulo: SMA, 2013.

SÃO PAULO. PDUI - Plano Diretor Urbano Integrado. Questões Metropolitanas. Disponível em <https://www.pdui.sp.gov.br/rmsp/?page_id=160>. Acesso em 8.05.2017. 